\title{
Effect of the Degradation of Cytochrome P-450 Heme by Secobarbital on Polychlorinated Biphenyls (PCB)-Induced Hepatic Vitamin A Reduction and Lipid Peroxide Formation in Rats ${ }^{1}$
}

\author{
Morio SaIto, * Sachie IKegami, Toshihiro Aizawa, \\ and Satoshi INNAMI ${ }^{2}$ \\ Division of Food Science, The National Institute of Nutrition, \\ 23-1, Toyama 1-chome, Shinjuku-ku, Tokyo 162, Japan
}

(Received December 24, 1982)

Summary The present studies were conducted to characterize the relevance of a microsomal mixed function oxidase system to the polychlorinated biphenyls (PCB)-induced vitamin A reduction and endogenous lipid peroxide formation in the liver of rats. And also, this study dealt with an influence of scavengers on the hepatic lipid peroxide formation stimulated by PCB. Rats were given a $0.01 \%$ PCB diet supplemented with adequate nutrients, for 14 days. In an experiment, secobarbital was injected subcutaneously for the degradation of hepatic microsomal cytochrome P-450 heme. A marked liver enlargement and a significant increase of total liver lipid content were observed in the PCB group. The secobarbital enhanced the PCB-induced liver enlargement but no effect of secobarbital on the lipid content was recognized. PCB significantly induced hepatic microsomal cytochrome P-450, but not both cytochrome $b_{5}$ and NADPH-cytochrome $c$ reductase. The secobarbital suppressed the induction of cytochrome P-450 caused by PCB to approximately one-half. The hepatic vitamin A content significantly decreased on PCB administration and the secobarbital slightly enhanced the PCB-induced vitamin A reduction. However, the vitamin A content in the secobarbital-injected control group decreased to nearly the same levels as in the PCB groups. Therefore, it was presumed that the hepatic microsomal mixed function oxidase system, especially the cytochrome P-450, was possibly not directly involved in the PCB-induced hepatic vitamin A reduction or that a metabolic system related to mixed function oxidase system was involved in

${ }^{1}$ Polychlorinated biphenyls toxicity and nutrition. XVI. Polychlorinated biphenyls toxicity and vitamin A (8).

2 斎藤衛郎, 池上幸江, 相沢利弘, 印南 敏

* To whom all correspondence should be addressed.

Abbreviation: $\mathrm{PCB}$, polychlorinated biphenyls. 
the reduction. On the other hand, the hepatic lipid peroxide content tended to increase on PCB administration though no significant difference was recognized. In contrast, the hepatic lipid peroxide content significantly increased in the secobarbital-injected PCB group as compared with the secobarbital-injected control group. However, there was no difference in the lipid peroxide contents between the control groups with and without the injection of secobarbital, and also between the PCB groups. The hepatic vitamin $\mathrm{E}$ contents lowered in the secobarbitalinjected groups but no effect was observed on PCB administration. The glutathione peroxidase activity decreased significantly on PCB administration and the secobarbital further decreased the activity. Therefore, it was suggested that the significant increase and tendency of increase in hepatic lipid peroxide contents in the PCB groups with and without injection of secobarbital were ascribed to an insufficiency of lipid peroxide scavengers in the liver. And also, it was supposed that the degradation of hepatic microsomal cytochrome P-450 heme caused by secobarbital was not responsible for the hepatic lipid peroxide formation on PCB administration, indicating that the cytochrome P-450 was possibly not directly involved in the PCB-induced hepatic lipid peroxidation.

Key Words PCB, vitamin A, mixed function oxidase system, cytochrome $\mathrm{P}-450$, secobarbital, lipid peroxide formation, vitamin $\mathrm{E}$, glutathione peroxidase

It has been reported that animals ingesting polychlorinated biphenyls (PCB) exhibit not only increased lipid peroxide formation(1-5) but also vitamin A reduction $(1,2,6-8)$ in the liver.

Roberts and DeLuca (9) showed that decarboxylation of retinoic acid in vitro was initiated by a free radical mechanism resembling that in lipid peroxidation. So we investigated the relevance of the lipid peroxidation to the vitamin A reduction in the liver of rats given $\mathrm{PCB}$, and found that lipid peroxidation was unlikely to be involved in the PCB-induced hepatic vitamin A reduction $(1,2)$.

It is well known that PCB induce the hepatic microsomal mixed function oxidase system and PCB themselves are also metabolized by this system. We showed that the increment in hepatic microsomal cytochrome P-450 content and decrease in hepatic vitamin A content of rats occurred as PCB levels in the diet increased (1). Kato et al. (10) also reported that PCB caused reduction of pentobarbital sleeping time and of hepatic vitamin A content in rats, which was enhanced with high protein diet as compared with that of low protein. Further, Roberts et al. (11-13) revealed that retinoic acid was converted into the inactive metabolite by the enzyme having properties similar to hepatic microsomal cytochrome P-450 and that this conversion was not inhibited by peroxidation inhibitors. Therefore, it is presumed that the hepatic microsomal mixed function oxidase system containing cytochrome $\mathrm{P}-450$ or relating metabolic system affects the reduction of vitamin $\mathrm{A}$ in the liver of 
animals given PCB.

On the other hand, PCB increase hepatic lipid peroxide formation but so far the detailed mechanism has remained unclear, especially in vivo. In our previous papers $(2,14,15)$ it was found that the increment in hepatic lipid peroxide formation caused by PCB was partly due to the increase in polyunsaturated fatty acids, substrate for lipid peroxide, and to the insufficiency of lipid peroxide scavengers.

It is well known that NADPH-dependent flavoenzyme, NADPH-cytochrome $c$ reductase, catalyzes hepatic microsomal lipid peroxidation in vitro $(16,17)$. It was also reported that hepatic microsomal cytochrome P-450 was directly involved in the intracellular formation of lipid peroxide (18). Furthermore, Svingen et al. (19) suggested that the cytochrome P-450 catalyzed the propagation of lipid peroxidation in vitro in hepatic microsomes. As PCB induce the hepatic microsomal mixed function oxidase system containing NADPH-cytochrome $c$ reductase and cytochrome P-450(20), it might be assumed that the system is responsible for the lipid peroxide formation in the liver of animals given PCB.

The present studies were carried out to find out the influences of the degradation of cytochrome P-450 heme caused by secobarbital on PCB-induced hepatic vitamin A reduction and lipid peroxide formation in rats.

\section{MATERIALS AND METHODS}

Preparation of animals and diets. Weanling male rats of the Sprague-Dawley strain weighing an average of $62 \mathrm{~g}$ (ranging 58-67 g, 3 weeks of age) were housed individually in wire cages in an animal laboratory kept at a constant temperature of $23 \pm 1^{\circ} \mathrm{C}$ and a 12-h cycle of light (7:00-19:00 h) and dark. The composition of the basal diet was the same as described in the previous paper(2). Vitamin E ( $d l-\alpha-$ tocopheryl acetate) was added to the diet at the level of $10 \mathrm{mg} \%$ in this experiment. PCB were added to the diet at the level of $0.01 \%$ and the amount of PCB was substituted for an equal part of sucrose. After being fed on a basal diet for three days, six or eight rats from each group were maintained on the experimental diets for two weeks. Food and water were given ad libitum throughout the experiments. Food consumption and body weight were recorded four times a week. In an experiment, secobarbital sodium was used for the degradation of cytochrome P-450 heme and was injected subcutaneously into the back between 6:00 and 7:00 p.m., first four days at a dose of $35 \mathrm{mg} / \mathrm{kg} \mathrm{B}$.W./day, next seven days $50 \mathrm{mg} / \mathrm{kg} \mathrm{B}$.W./day, and last three days $75 \mathrm{mg} / \mathrm{kg} \mathrm{B}$.W./day. At the end of the experimental period, the food cups were removed at 7:00 a.m. After starving rats for 7 to $8 \mathrm{~h}$, the animals were sacrificed by decapitation. The liver was promptly excised, washed with isotonic saline, and weighed. The left lobe of the liver was perfused with ice-cold isotonic saline via the portal vein and immediately analyzed for endogenous lipid. peroxide content. The other part of the liver was stored at $-20^{\circ} \mathrm{C}$ until analysis.

Analytical methods. Determination of hepatic vitamins A (retinol) and E ( $\alpha$ tocopherol) was carried out by a spectrofluorometric method lined with high 
performance liquid chromatograph (HPLC) as described in the previous papers $(1,2)$. Serum vitamins $\mathrm{A}$ and $\mathrm{E}$ were assayed by virtually the same method as for the hepatic vitamins except that the sera were directly extracted with $n$-hexane and the extracts were subjected to HPLC. Endogenous hepatic lipid peroxide content was determined by the method of Masugi and Nakamura (21) using thiobarbituric acid (TBA) reaction and was expressed in terms of malondialdehyde (MDA) formed. Glutathione peroxidase activity in the liver was determined according to the method of Noguchi et al. (22) except for the concentration of liver homogenate, from $2.0 \%$ to $1.67 \%$, and hydrogen peroxide as substrate, from $4.17 \mathrm{~mm}$ to $1.25 \mathrm{~mm}$. Hepatic microsomes were prepared as follows. The liver perfused with ice-cold isotonic saline via the portal vein was homogenized with nine volumes of ice-cold isotonic $(1.15 \%)$ potassium chloride solution using a Teflon Potter-Elvehjem homogenizer. The homogenate was centrifuged at $10,000 \times g$ for $15 \mathrm{~min}$ in a refrigerated centrifuge, Hitachi model $55 \mathrm{p}-2$ preparative ultracentrifuge, and the supernate was separated from the precipitate. The microsomes were sedimented from the $10,000 \times g$ supernate by centrifugation at $78,000 \times g$ for $90 \mathrm{~min}$. The firmly packed pellet of microsomes was resuspended in isotonic potassium chloride solution with Potter-Elvehjem homogenizer and again centrifuged as above. The washed microsomes were finally suspended in $0.1 \mathrm{M}$ potassium phosphate buffer, $\mathrm{pH} 7.5$, containing $20 \%(\mathrm{v} / \mathrm{v})$ glycerol. The resultant microsomal suspensions were assayed for cytochromes P-450 and $b_{5}$ contents (23), and NADPH-cytochrome $c$ reductase activity (24) by the method of Omura and Sato, and Omura and Takesue respectively.

Chemicals. The PCB used in this experiment were purchased from Wako Pure Chemical Industries Ltd. They consisted of a mixture of the isomers, the dominant components of which were tetrachlorides. Secobarbital sodium (sodium 5-allyl-5-(1methylbutyl)barbiturate) was purchased from Yoshitomi Pharmaceutical Industries Co. Retinyl acetate and $d l-\alpha$-tocopherol were obtained from Wako Pure Chemical Industries Ltd. Glutathione (reduced form), NADH (Grade III), NADPH (Type I) and cytochrome $c$ (Type III) were purchased from Sigma Chemical Co. Other reagents used in this experiment were of analytical grade.

Statistical analysis. Student's $t$ test was used to determine significant differences between treatment means. The level of significance chosen was $p<0.05$.

\section{RESULTS}

\section{Effect of $P C B$ on vitamin $A$ reduction and lipid peroxide formation}

The rats were given the experimental diet containing $0.01 \%$ PCB for 14 days. Changes in food intake, body weight gain, and liver weight are given in Table 1. Food intake and body weight gain in the PCB group were not different from respective control values, whereas an increase in liver weight was observed in the PCB group. Hepatic microsomal cytochromes P-450 and $b_{5}$ contents, and NADPHcytochrome $c$ reductase activity are shown in Table 2. Cytochrome P-450 content in 
Table 1. Food intake, body weight gain and liver weight in rats fed diet containing $0.01 \%$ PCB for 14 days.

\begin{tabular}{ccc}
\hline & \multicolumn{2}{c}{ Group } \\
\cline { 2 - 3 } Items & Control & PCB \\
\hline $\begin{array}{c}\text { Food intake } \\
\text { (g/day) }\end{array}$ & $12.5 \pm 0.4^{1, \mathrm{a}}$ & $12.9 \pm 0.7^{\mathrm{a}}$ \\
$\begin{array}{c}\text { Body weight } \\
\text { gain (g) }\end{array}$ & $84.7 \pm 2.0^{\mathrm{a}}$ & $84.4 \pm 4.1^{\mathrm{a}}$ \\
$\begin{array}{c}\text { Liver weight } \\
\text { (g/100 }\end{array}$ & $4.26 \pm 0.09^{\mathrm{a}}$ & \\
\hline
\end{tabular}

${ }^{1}$ Mean \pm SEM for 6 rats. Means not sharing a common superscript letter are significantly different $(p<0.05)$.

Table 2. Hepatic microsomal cytochromes P-450 and $b_{5}$ contents and NADPHcytochrome $c$ reductase activity in rats fed diet containing $0.01 \%$ PCB for 14 days.

\begin{tabular}{ccc}
\hline & \multicolumn{2}{c}{ Group } \\
\cline { 2 - 3 } Items & Control & PCB \\
\hline $\begin{array}{c}\text { Cytochrome P-450 content } \\
(\text { nmol/g liver) }\end{array}$ & $7.38 \pm 0.41^{1, \mathrm{a}}$ & $12.89 \pm 1.55^{\mathrm{b}}$ \\
$\begin{array}{c}\text { Cytochrome } b_{5} \text { content } \\
(\text { nmol/g liver) }\end{array}$ & $3.99 \pm 0.13^{\mathrm{a}}$ & $5.47 \pm 0.76^{\mathrm{a}}$ \\
$\begin{array}{c}\text { NADPH-cytochrome } c \\
\text { reductase activity } \\
(\mu \text { mol/min/g liver })\end{array}$ & $0.63 \pm 0.04^{\mathrm{a}}$ & $0.67 \pm 0.10^{\mathrm{a}}$ \\
\hline
\end{tabular}

${ }^{1}$ Mean \pm SEM for 6 rats. Means not sharing a common superscript letter are significantly different $(p<0.05)$.

the PCB group increased approximately 2-fold over that of the control group, while cytochrome $b_{5}$ content and NADPH-cytochrome $c$ reductase activity in the PCB group were not different from the control group. As shown in Fig. 1, hepatic vitamin A content significantly decreased in the PCB group and the content was about one-half that of the control group. Therefore, the increase in hepatic microsomal cytochrome P-450 content might seem to correlate with the decrease in hepatic vitamin A content.

The hepatic lipid peroxide (TBA value) and vitamin E contents tended to increase in the PCB group but no significant differences were recognized (Table 3). 


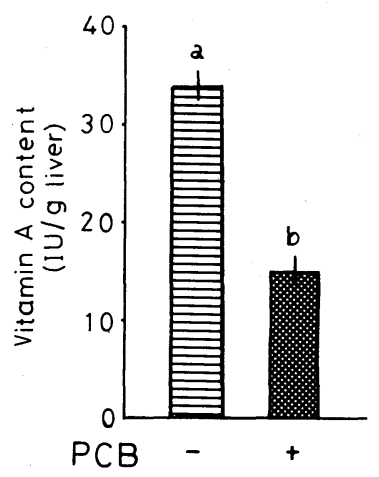

Fig. 1. Hepatic vitamin A content in rats fed diet containing $0.01 \%$ PCB for 14 days. Each bar represents mean \pm SEM for 6 rats. Bars not sharing a common letter are significantly different $(p<0.05)$.

Table 3. Contents of hepatic lipid peroxide (TBA value) and vitamin $\mathrm{E}$ in rats fed diet containing $0.01 \%$ PCB for 14 days.

\begin{tabular}{|c|c|c|}
\hline \multirow{2}{*}{ Items } & \multicolumn{2}{|c|}{ Group } \\
\hline & Control & PCB \\
\hline $\begin{array}{l}\text { TBA value }^{1} \\
(\mu \text { mol MDA } / \mathrm{g} \text { liver })\end{array}$ & $0.157 \pm 0.009^{2, a}$ & $0.173 \pm 0.008$ \\
\hline $\begin{array}{l}\text { V.E content } \\
(\mu \mathrm{g} / \mathrm{g} \text { liver })\end{array}$ & $35.3 \pm 3.4^{\mathrm{a}}$ & $46.6 \pm 5.9^{\mathrm{a}}$ \\
\hline
\end{tabular}

Effects of PCB and the degradation of cytochrome P-450 heme caused by secobarbital on vitamin $A$ reduction and lipid peroxide formation

We conducted the experiment to see if the hepatic microsomal mixed function oxidase system, especially cytochrome P-450, was responsible for the vitamin A reduction and lipid peroxide formation in the liver of rats given PCB. For this purpose, effect of the degradation of the cytochrome heme caused by secobarbital was examined.

The normal and $0.01 \%$ PCB diets were fed to rats with or without the subcutaneous injection of secobarbital. Changes in food intake, body weight gain, liver weight, and total liver lipid content are shown in Table 4. There was no difference in food intake between the control and PCB groups without injection of secobarbital. However, food intake was significantly suppressed by injection of 
Table 4. Effect of the degradation of cytochrome P-450 heme by secobarbital on food intake, body weight gain, liver weight and total liver lipid content in rats given diets with and without PCB for 14 days.

\begin{tabular}{lcccc}
\hline $\begin{array}{l}\text { PCB }^{1} \\
\text { Secobarbital }^{2}\end{array}$ & - & + & - & + \\
\hline $\begin{array}{c}\text { Food intake } \\
\text { (g/day) }\end{array}$ & $13.9 \pm 0.3^{3, \mathrm{a}}$ & $13.1 \pm 0.3^{\mathrm{a}}$ & $11.7 \pm 0.3^{\mathrm{b}}$ & $10.6 \pm 0.3^{\mathrm{c}}$ \\
$\begin{array}{c}\text { Body weight } \\
\text { gain (g) }\end{array}$ & $84.0 \pm 2.6^{\mathrm{a}}$ & $79.0 \pm 3.1^{\mathrm{a}}$ & $79.0 \pm 1.4^{\mathrm{a}}$ & $65.9 \pm 1.9^{\mathrm{b}}$ \\
$\begin{array}{c}\text { Liver weight } \\
\text { (g/100 } \mathrm{g} \mathrm{B.W.})\end{array}$ & $3.94 \pm 0.11^{\mathrm{a}}$ & $5.54 \pm 0.23^{\mathrm{b}}$ & $5.11 \pm 0.07^{\mathrm{b}}$ & $6.53 \pm 0.12^{\mathrm{c}}$ \\
$\begin{array}{c}\text { Total liver } \\
\text { lipid content } \\
(\mathrm{mg} / \mathrm{g} \text { liver) }\end{array}$ & $81.1 \pm 3.4^{\mathrm{a}}$ & $97.9 \pm 4.6^{\mathrm{b}}$ & $71.0 \pm 3.9^{\mathrm{a}}$ & $106.1 \pm 5.0^{\mathrm{b}}$ \\
\hline
\end{tabular}

${ }^{1}$ PCB were added to the diet at the level of $0.01 \%$. ${ }^{2}$ Secobarbital was injected subcutaneously as described in MATERIALS AND METHODS. ${ }^{3}$ Mean \pm SEM for 8 rats. Means not sharing a common superscript letter are significantly different $(p<0.05)$.

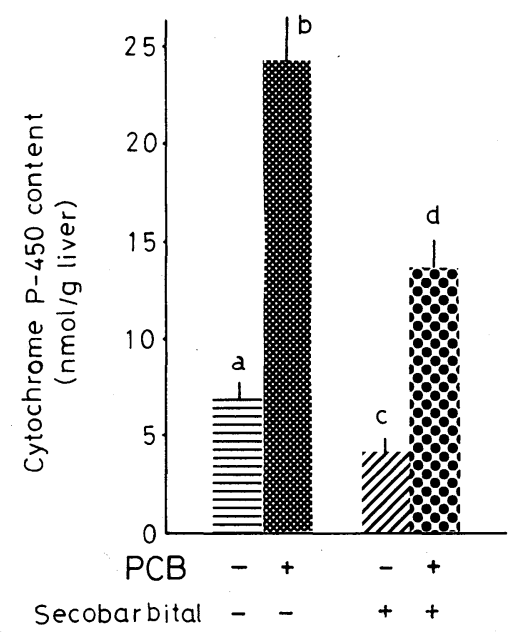

Fig. 2. Effect of the degradation of cytochrome P-450 heme by secobarbital on hepatic microsomal cytochrome P-450 content in rats given diets with and without PCB for 14 days. PCB were added to the diet at the level of $0.01 \%$. Each bar represents mean \pm SEM for 8 rats. Bars not sharing a common letter are significantly different $(p<0.05)$.

secobarbital, particularly in the PCB group. A decrease in body weight gain was observed only in the secobarbital-injected PCB group. Both administration of PCB and injection of secobarbital increased the liver weight and especially a marked liver Vol. 29, No. 4, 1983 
enlargement was observed with combination of them. Dietary PCB also increased the total liver lipid content regardless of injection of secobarbital. Therefore, an enlargement of the liver caused by PCB was thought to be due to the accumulation of lipids. In contrast, an enlargement of the liver in the secobarbital-injected control group was not accompanied by an increase in the lipid content. The enlargement of liver caused by secobarbital seemed to be attributable to a hyperfunction to metabolize secobarbital. Therefore, the marked increase in liver weight in the secobarbital-injected PCB group was thought to be ascribed to an additive effect of both PCB and secobarbital. As shown in Fig. 2, the induction of hepatic microsomal cytochrome P-450 was observed on PCB administration but the raised induction, was suppressed to approximately one-half with injection of secobarbital as compared with that of the PCB group without injection. The cytochrome P-450 content in the secobarbital-injected control group also significantly decreased less than that of the control group without injection of secobarbital. Though the data are not shown, the contents of cytochrome P-450 expressed per mg protein were similar to those expressed per $\mathrm{g}$ liver. Hepatic vitamin A content and serum vitamin A concentration are indicated in Fig. 3. PCB feeding caused significant decrease in the hepatic vitamin $\mathrm{A}$ content and the injection of secobarbital slightly enhanced the PCB-induced vitamin A reduction. However, the vitamin A content in the secobarbital-injected control group decreased to nearly the same levels as those in the PCB groups, suggesting that
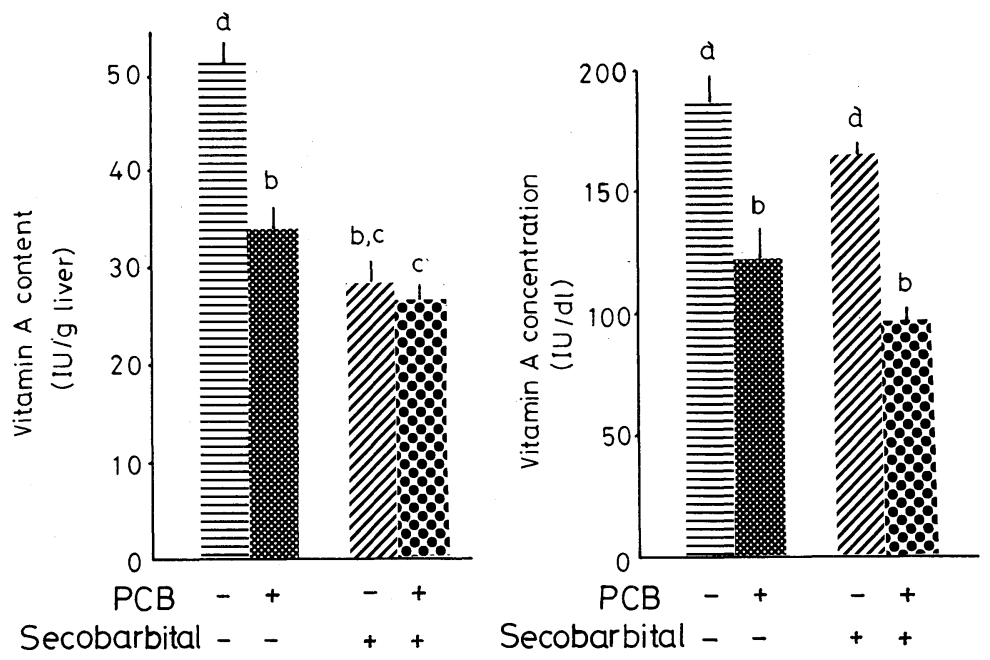

Fig. 3. Effect of the degradation of cytochrome P-450 heme by secobarbital on hepatic vitamin A content (left) and serum vitamin A concentration (right) in rats given diets with and without PCB for 14 days. PCB were added to the diet at the level of $0.01 \%$. Each bar represents mean \pm SEM for 8 rats. Bars not sharing a common letter are significantly different $(p<0.05)$. 


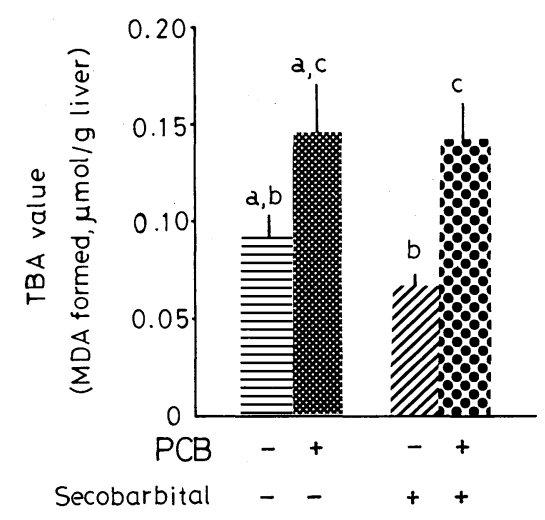

Fig. 4. Effect of the degradation of cytochrome P-450 heme by secobarbital on hepatic TBA value in rats given diets with and without PCB for 14 days. PCB were added to the diet at the level of $0.01 \%$. Each bar represents mean \pm SEM for 8 rats. Bars not sharing a common letter are significantly different $(p<0.05)$.

Table 5. Effect of the degradation of cytochrome P-450 heme by secobarbital on hepatic vitamin $\mathrm{E}$ content, serum vitamin $\mathrm{E}$ concentration and hepatic glutathione peroxidase (GSHPx) activity in rats given diets with and without PCB for 14 days.

\begin{tabular}{lcccc}
\hline PCB $^{1}$ & - & + & - & + \\
Secobarbital $^{2}$ & - & - & + & + \\
\hline $\begin{array}{l}\text { Hepatic V.E content } \\
\quad(\mu \mathrm{g} / \mathrm{g} \text { liver })\end{array}$ & $41.0 \pm 4.3^{3, \mathrm{ac}}$ & $41.8 \pm 3.2^{\mathrm{a}}$ & $29.1 \pm 3.1^{\mathrm{b}}$ & $31.1 \pm 3.4^{\mathrm{bc}}$ \\
$\quad(\mu \mathrm{g} / \mathrm{mg}$ liver lipid $)$ & $0.50 \pm 0.05^{\mathrm{a}}$ & $0.41 \pm 0.04^{\mathrm{ab}}$ & $0.39 \pm 0.04^{\mathrm{ab}}$ & $0.31 \pm 0.02^{\mathrm{b}}$ \\
$\begin{array}{c}\text { Serum V.E concentration } \\
\quad(\mathrm{mg} / \mathrm{dl})\end{array}$ & $0.77 \pm 0.05^{\mathrm{a}}$ & $1.14 \pm 0.07^{\mathrm{b}}$ & $0.84 \pm 0.06^{\mathrm{a}}$ & $0.90 \pm 0.08^{\mathrm{a}}$ \\
$\begin{array}{c}\text { Hepatic GSHPx activity } \\
\quad(\text { unit/g liver })\left(\times 10^{3}\right)\end{array}$ & $2.58 \pm 0.14^{\mathrm{a}}$ & $1.70 \pm 0.13^{\mathrm{b}}$ & $2.00 \pm 0.13^{\mathrm{b}}$ & $1.33 \pm 0.10^{\mathrm{c}}$ \\
\hline
\end{tabular}

${ }^{1} \mathrm{PCB}$ were added to the diet at the level of $0.01 \%$. ${ }^{2}$ Secobarbital was injected subcutaneously as described in MATERIALS AND METHODS. ${ }^{3}$ Mean \pm SEM for 8 rats. Means not sharing a common superscript letter are significantly different $(p<0.05)$.

secobarbital itself functioned to reduce the vitamin A storage in the liver of rats. Since there was no difference in hepatic vitamin A contents in both the secobarbitalinjected groups, no additive or synergic action of secobarbital with PCB on the hepatic vitamin A reduction was observed. Therefore, the difference of the vitamin A contents between the PCB groups with and without the injection of secobarbital would be due in part to the difference of food intake, that is, vitamin A intake in these groups. The serum vitamin A concentration significantly decreased on PCB administration but no effect was observed with injection of secobarbital. 
The influence of PCB and secobarbital on hepatic lipid peroxide content (TBA value) is presented in Fig. 4. The hepatic lipid peroxide content tended to increase in the PCB group without injection of secobarbital but no significant difference was recognized. In contrast, in the secobarbital-injected PCB group the lipid peroxide content significantly increased as compared with the secobarbital-injected control group. However, there was no difference in the lipid peroxide contents between the control groups with and without the injection of secobarbital, and also between the PCB groups. Levels of lipid peroxide scavengers, vitamin E and glutathione peroxidase, are shown in Table 5. The hepatic vitamin E contents expressed per $g$ liver lowered in the secobarbital-injected groups but no effect was observed on PCB administration. When expressed per $\mathrm{mg}$ of liver lipid, the vitamin $\mathrm{E}$ contents tended to decline in the secobarbital-injected groups but no significant differences were recognized. The serum vitamin E concentration significantly increased only in the PCB group without injection of secobarbital. The glutathione peroxidase activity decreased on PCB administration and further decrease was observed with injection of secobarbital, clearly demonstrating an additive effect of secobarbital to PCB on the decrease in hepatic glutathione peroxidase activity. Though the data are not shown, the activities of glutathione peroxidase expressed per mg protein were similar to those expressed per $\mathrm{g}$ liver.

\section{DISCUSSION}

In the present study, we paid special attention to the possibility of involvement of the microsomal mixed function oxidase system, especially cytochrome P-450, in the PCB-induced vitamin A reduction and lipid peroxide production in the liver of rats. For revealing this possibility, secobarbital which causes a destruction of the cytochrome heme was employed, resulting in the suppression of PCB-stimulated induction of the cytochrome. And also, this study dealt with the effect of scavengers on the hepatic lipid peroxide formation of rats given PCB.

In view of the finding that PCB induced the hepatic microsomal cytochrome P450 and also caused hepatic vitamin A reduction, there might be a close correlation with each other. However, secobarbital significantly suppressed the PCB-stimulated induction of hepatic microsomal cytochrome P-450 but could not prevent the hepatic vitamin A reduction. Therefore, it is supposed that the hepatic microsomal cytochrome P-450 is possibly not directly involved in the PCB-induced hepatic vitamin A reduction, that is, in the vitamin A metabolism including catabolism. This as previously observed $(25,26)$ was supported by the finding that the level of induction of hepatic microsomal cytochrome P-450 caused by PCB was not necessarily parallel to the degree of reduction of hepatic vitamin $\mathrm{A}$ content. In addition, secobarbital itself also caused the hepatic vitamin A reduction similar to PCB. Roberts et al.(11-13) reported that retinoic acid was converted into the inactive metabolite by an enzyme having properties similar to hepatic microsomal cytochrome P-450. Therefore, it appears possible that both PCB and secobarbital 
induce the enzyme which metabolizes retinoic acid to deactivated metabolite, resulting in the reduction of hepatic vitamin A content.

Secobarbital causes a destruction of the hepatic microsomal cytochrome P-450 heme, and its mechanism is suggested that secobarbital is converted to an active metabolite such as epoxide by the hepatic microsomal mixed function oxidase system, leading to the destruction of cytochrome P-450 heme $(27,28)$. It is also suggested that this destruction of cytochrome P-450 heme is unrelated to lipid peroxidation (29). Therefore, an alternative mechanism might appear possible on the PCB-induced hepatic vitamin A reduction, that is, both PCB and secobarbital are converted to active metabolites by hepatic microsomal mixed function oxidase system and subsequently the metabolites might cause the hepatic vitamin A reduction. It has been reported that PCB are converted to active metabolites such as epoxides by microsomal mixed function oxidase system in the liver of animals $(30,31)$.

In contrast to this, no increase in hepatic lipid peroxide formation was recognized in the secobarbital-injected control group as compared with that of the control without secobarbital, clearly demonstrating that the lipid peroxidation was not associated with the decrease in hepatic vitamin A content caused by secobarbital. Levin et al.(29) also reported that secobarbital did not enhance the hepatic microsomal lipid peroxidation. In the present experimental condition, no significant increment in hepatic lipid peroxide formation was observed on PCB administration without injection of secobarbital though PCB tended to increase the hepatic lipid peroxide content. However, significant hepatic vitamin A reduction was ascertained to be caused by PCB administration, suggesting that in keeping with the previous observations $(1,2)$, the lipid peroxidation did not mediate the hepatic vitamin $\mathrm{A}$ reduction caused by $\mathrm{PCB}$, especially in vivo.

Although the serum vitamin A concentration significantly decreased on PCB administration, this differed from the liver where no effect of the secobarbital on the concentration was observed. We have previously reported that PCB cause a significant decrease of retinol binding protein in the serum (6). Therefore, it is easily conceivable that a decrease of retinol binding protein caused by PCB leads to the decline in the serum vitamin $A$ concentration and that the secobarbital is independent of a biosynthesis of retinol binding protein in the liver.

On the other hand, dietary PCB tended to increase the hepatic lipid peroxide content but no significant difference was observed. Therefore, it is obvious that a $10 \mathrm{mg} \%$ dietary level of vitamin $\mathrm{E}$ (usual level) is sufficient for suppressing the hepatic lipid peroxide formation caused by a $0.01 \%$ dietary level of PCB. In contrast to this, as previously reported(2), a higher level of dietary PCB significantly enhanced the hepatic lipid peroxide formation in rats.

Although there were no differences in the hepatic lipid peroxide contents between the control groups with and without the injection of secobarbital, and also between the PCB groups, the combination of PCB and secobarbital significantly increased the lipid peroxide, which was accompanied by the reductions of hepatic 
vitamin $\mathrm{E}$ content and glutathione peroxidase activity. The result implies that the enhancement of hepatic lipid peroxidation in rats fed PCB and injected secobarbital is ascribed to the insufficiency of lipid peroxide scavengers in the liver. Therefore, it appears possible that the degradation of cytochrome P-450 heme caused by secobarbital is independent of the hepatic lipid peroxide formation on PCB administration. As already described, the secobarbital itself did not enhance the hepatic lipid peroxidation in the present experiment and this was supported by other investigators (29).

Svingen et al. (19) suggested that cytochrome P-450 catalyzed the propagation of lipid peroxidation in vitro in hepatic microsomes. O'Brien and Rahimtula (18) reported that cytochrome P-450 was responsible for hepatic microsomal lipid peroxidation in which the cytochrome acted as a peroxidase with the lipid as a hydrogen donor resulting in a formation of lipid radicals and then lipid peroxides reacted with oxygen. Nordblom et al. (32) also showed the data for the action of hepatic microsomal cytochrome P-450 in which the cytochrome catalyzed the hydroperoxide-dependent hydroxylation of a variety of substrates. Furthermore, Dougherty et al.(33) reported the increase in lipid peroxidation in vivo caused by iron salts by measuring ethane production in rats. It is presumed from these results that the hepatic lipid peroxide formation caused by PCB varies via the PCBstimulated cytochrome P-450 induction and the degradation of cytochrome P-450 heme caused by secobarbital. However, no correlation between lipid peroxide formation (Fig. 4) and cytochrome P-450 content (Fig. 2) was observed in the control groups with and without the injection of secobarbital, and also in the PCB groups. Therefore, it is possible to deduce that the hepatic microsomal cytochrome $\mathrm{P}-450$ is not directly involved in the hepatic lipid peroxide formation. Baird (34) also suggested that cytochrome $\mathrm{P}-450$ did not have a catalytic role in the peroxidation of lipid in liver microsomes.

It is well known that initiation of lipid peroxidation in vitro in hepatic microsomes is catalyzed by NADPH-cytochrome $c$ reductase $(17,19)$. In the present experiment a $0.01 \%$ dietary level of PCB did not increase the NADPH-cytochrome $c$ reductase activity. However, since it has been shown that a higher level of dietary PCB $(0.1 \%)$ raises the activity of NADPH-cytochrome $c$ reductase (35), further investigations will be required to see if the NADPH-cytochrome $c$ reductase induced by a higher level of PCB would be involved in the initiation of hepatic lipid peroxidation.

\section{REFERENCES}

1) Innami, S., Ikegami, S., Saito, M., Nakamura, A., and Nagayama, S. (1982): Lack of responsibility of lipid peroxidation for reduction of vitamin $\mathrm{A}$ in the liver of rats given Polychlorinated Biphenyls. Nutr. Rep. Int., 25, 931-940.

2) Saito, M., Ikegami, S., Ito, Y., and Innami, S. (1982): Influence of dietary antioxidants on polychlorinated biphenyls (PCB)-induced hepatic lipid peroxide formation and vitamin A reduction in rats. J. Nutr. Sci. Vitaminol., 28, 455-466. 
3) Itokawa, Y., Yagi, N., Kaito, H., Kamohara, K., and Fujiwara, K. (1976): Influence of diet on the induction of hepatic ceroid pigment in rats by Polychlorinated Biphenyls. Toxicol. Appl. Pharmacol., 36, 131-141.

4) Combs, G. F., Jr., and Scott, M. L. (1975): Polychrorinated biphenyl-stimulated selenium deficiency in the chick. Poultry Sci., 54, 1152-1158.

5) Ito, Y., and Murata, T. (1980): Lipid peroxidation in the hepatopancreas of carp by PCB-treatment. Nippon Nogeikagaku Kaishi (J. Agric. Chem. Soc. Jpn.), 54, $263-270$.

6) Innami, S., Nakamura, A., Miyazaki, M., Nagayama, S., and Nishide, E. (1976): Further studies on the reduction of vitamin A content in the livers of rats given polychlorinated biphenyls. J. Nutr. Sci. Vitaminol., 22, 409-418.

7) Villenuve, D. C., Grant, D. L., Phillips, W. E. J., Clark, M. L., and Clegg, D. J. (1971): Effects of PCB administration on microsomal enzyme activity in pregnant rabbits. Bull. Environ. Contam. Toxicol., 6, 120-128.

8) Ceil, H. C., Harris, S. J., Bitman, J., and Fries, G. F. (1973): Polychlorinated Biphenylinduced decrease in liver vitamin A in Japanese quail and rats. Bull. Environ. Contam. Toxicol., 9, 179-187.

9) Roberts, A. B., and DeLuca, H. F. (1968): Oxidative decarboxylation of retinoic acid in microsomes of rat liver and kidney. J. Lipid Res., 9, 501-508.

10) Kato, N., Kato, M., Kimura, T., and Yoshida, A. (1978): Effect of dietary addition of PCB, DDT or BHT and dietary protein on vitamin A and cholesterol metabolism. Nutr. Rep. Int., 18, 437-445.

11) Roberts, A. B., Nichols, M. D., Newton, D. L., and Sporn, M. B. (1979): In vitro metabolism of retinoic acid in hamster intestine and liver. J. Biol. Chem., 254, 62966302.

12) Roberts, A. B., Lamb, L. C., and Sporn, M. B. (1980): Metabolism of all-trans retinoic acid in hamster liver microsomes: Oxidation of 4-hydroxy- to 4-keto-retinoic acid. Arch. Biochem. Biophys., 199, 374-383.

13) Roberts, A. B., and Frolik, C. A. (1979): Recent advances in the in vivo and in vitro metabolism of retinoic acid. Fed. Proc., 38, 2524-2527.

14) Innami, S., Nakamura, A., Ono, S., and Nagayama, S. (1978): Effects of dietary lipids on growth and lipid metabolism in rats given Polychlorinated Biphenyls. Eiyogaku Zasshi (Jpn. J. Nutr.), 36, 215-224.

15) Innami, S., Ono, S., Nakamura, A., Ikegami, S., Nagayama, S., and Nishide, E. (1979): Effect of Polychlorinated Biphenyls (PCB) on lipid peroxide formation in rats. Fukuoka Igaku Zasshi (Fukuoka Acta Med.), 70, 102-108.

16) Hochstein, P., and Ernster, L. (1963): ADP-activated lipid peroxidation coupled to the reduced TPNH oxidase system of microsomes. Biochem. Biophys. Res. Commun., 12, 388-394.

17) Pederson, T. C., Buege, J. A., and Aust, S. D. (1973): Microsomal electron transport. The role of reduced nicotinamide adenine dinucleotide phosphate-cytochrome $c$ reductase in liver microsomal lipid peroxidation. J. Biol. Chem., 248, 7134-7141.

18) O'Brien, P. J., and Rahimtula, A. (1975): Involvement of cytochrome P-450 in the intracellular formation of lipid peroxides. J. Agric. Food Chem., 23, 154-158.

19) Svingen, B. A., Buege, J. A., O'Neal, F. O., and Aust, S. D. (1979): The mechanism of NADPH-dependent lipid peroxidation. The propagation of lipid peroxidation. J. Biol. Chem., 254, 5892-5899.

20) Alvares, A. P., and Kappas, A. (1977): Heterogeneity of cytochrome P-450s induced by Polychlorinated Biphenyls. J. Biol. Chem., 252, 6373-6378.

21) Masugi, F., and Nakamura, T. (1977): Measurement of thiobarbituric acid value in

Vol. 29, No. 4, 1983 
liver homogenate solubilized with sodium dodecylsulphate and variation of the values affected by vitamin E and drugs. Vitamins (J. Vit. Soc. Jpn.), 51, 21-29.

22) Noguchi, T., Cantor, A. H., and Scott, M. L. (1973): Mode of action of selenium and vitamin $\mathrm{E}$ in prevention of exudative diathesis in chicks. J. Nutr., 103, 1502-1511.

23) Omura, T., and Sato, R. (1964): The carbon monoxide-binding pigment of liver microsomes. I. Evidence for its hemoprotein nature. J. Biol. Chem., 239, 2370-2378.

24) Omura, T., and Takesue, S. (1970): A new method for simultaneous purification of cytochrome $b_{5}$ and NADPH-cytochrome $c$ reductase from rat liver microsomes. $J$. Biochem., 67, 249-258.

25) Ikegami, S., Saito, M., Nagayama, S., Innami, S., and Nishide, E. (1980): Effect of vitamin $E$ levels in diets on vitamin A content and lipid peroxide formation in the liver of PCB-administered rats. Eiyogaku Zasshi (Jpn. J. Nutr.), 38, 303-309.

26) Ikegami, S., Nakamura, A., Ono, S., Nagayama, S., and Innami, S. (1980): Effect of combination of PCB and BHC on vitamin A storage and lipid peroxide formation in liver of rats. Eiyo To Shokuryo (J. Jpn. Soc. Food Nutr.), 33, 327-333.

27) De Matteis, F. (1971): Loss of haem in rat liver caused by the porphyrogenic agent 2allyl-2-isopropylacetamide. Biochem. J., 124, 767-777.

28) Levin, W., Sernatinger, E., Jacobson, M., and Kuntzman, R. (1972): Destruction of cytochrome P-450 by secobarbital and other barbiturates containing allyl groups. Science, 176, 1341-1343.

29) Levin, W., Lu, A. Y. H., Jacobson, M., and Kuntzman, R. (1973): Lipid peroxidation and the degradation of cytochrome P-450 heme. Arch. Biochem. Biophys., 158, 842-852.

30) Seymour, J. L., Schmidt, S. P., and Allen, J. R. (1976): In vitro generation of a chemically reactive metabolite of 2,5,2',5'-tetrachlorobiphenyl by rehesus monkey liver microsomes. Proc. Soc. Exp. Biol. Med., 152, 621-625.

31) Shimada, T., and Sato, R. (1978): Covalent binding in vitro of polychlorinated biphenyls to microsomal macromolecules. Involvement of metabolic activation by a cytochrome P-450-liked mono-oxygenase system. Biochem. Pharmacol., 27, 585-593.

32) Nordblom, G. D., White, R. E., and Coon, M. J. (1976): Studies on hydroperoxidedependent substrate hydroxylation by purified liver microsomal cytochrome P-450. Arch. Biochem. Biophys., 175, 524-533.

33) Dougherty, J. J., Croft, W. A., and Hoekstra, W. G. (1981): Effects of ferrous chloride and iron-dextran on lipid peroxidation in vivo in vitamin $\mathrm{E}$ and selenium adequate and deficient rats. J. Nutr., 111, 1784-1796.

34) Baird, M. B. (1980): Microsomal NADPH-dependent lipid peroxidation does not require the presence of intact cytochrome P-450. Biochem. Biophys. Res. Commun., 95, $1510-1516$.

35) Kato, N., Tani, T., and Yoshida, A. (1980): Effect of dietary level of protein on liver microsomal drug-metabolizing enzymes, urinary ascorbic acid and lipid metabolism in rats fed PCB-containing diets. J. Nutr., 110, 1686-1694. 